\title{
化学镀制备高温质子导体镍电极及其电化学性能
}

\author{
温亚兵 ${ }^{1,2}$, 张敬超 ${ }^{2}$, 叶晓峰 ${ }^{2}$, 王 勇 ${ }^{1}$, 韩金铎 ${ }^{2}$, \\ 罗文华 ${ }^{3}$, 谷 穗 $^{2}$, 孟建波 ${ }^{3}$, 温兆银 ${ }^{2}$
}

(1. 上海大学 环境与化学工程学院, 上海 200444; 2. 中国科学院 上海硅酸盐研究所 中国科学院能量转换材料重 点实验室, 上海 200050; 3. 中国工程物理研究院 材料研究所, 绵阳 621900)

摘 要: 采用化学镀在高温质子导体 $\mathrm{CaZr}_{0.9} \mathrm{In}_{0.1} \mathrm{O}_{3-\delta}(\mathrm{CZI})$ 的电解质陶瓷表面沉积金属镍电极, 通过 $\mathrm{SEM}$ 显微结构 分析比较了酸刻蚀和还原工艺对电极形貌以及电极-电解质界面的影响。结果表明, 使用 $\mathrm{HNO}_{3}-\mathrm{HCl}$ 混合刻蚀液, 并 以水合肼为还原剂的二次化学镀可获得颗粒均匀细小且界面结合良好的镍电极。通过电化学阻抗谱并结合浓差电 池等方法研究比较了以化学镀镍电极和涂覆焙烧铂电极为电极, CZI 为电解质的对称电池的电导率和质子迁移率。 工作温度为 $800^{\circ} \mathrm{C}$ 时, 镍电极高温质子导体的总电导率为 $4.131 \times 10^{-4} \mathrm{~S} / \mathrm{cm}$, 并且工作温度在 $400^{\circ} \mathrm{C}$ 以上时, 镍电极 对称电池的质子迁移率均接近 $100 \%$ 。这些结果表明, 二次化学镀制备的镍电极具有与铂电极相近的电化学性能, 而成本则更低，可以取代 Pt 电极用于高温质子导体的电化学器件中。

关 键 词: 化学镀; 镍电极; 高温质子导体

中图分类号: 0646 文献标识码: A

\section{Nickle Electrodes for High-temperature Proton-conducting Electrolytes: Prepa- ration by Electroless Plating and Electrochemical Performance}

\author{
WEN Ya-Bing ${ }^{1,2}$, ZHANG Jing-Chao ${ }^{2}$, YE Xiao-Feng ${ }^{2}$, WANG Yong ${ }^{1}$, HAN Jin-Duo ${ }^{2}$, \\ LUO Wen-Hua ${ }^{3}$, GU Sui ${ }^{2}$, MENG Jian-Bo ${ }^{3}$, WEN Zhao-Yin ${ }^{2}$
}

(1. School of Environmental and Chemical Engineering, Shanghai University, Shanghai 200444, China; 2. CAS Key Laboratory of Materials for Energy Conversion, Shanghai Institute of Ceramics, Chinese Academy of Sciences, Shanghai 200050, China; 3. China Academy of Engineering Physics, Sichuan 621900, China)

\begin{abstract}
Nickel layers were deposited on the surface of high-temperature proton-conducting $\operatorname{CaZr}_{0.9} \mathrm{In}_{0.1} \mathrm{O}_{3-\delta}(\mathrm{CZI})$ electrolytes by an electroless plating technique. Effects of acid etching and reduction processes on electrode surface morphology and electrolyte adherence to electrodes were investigated by SEM observation. The results showed that the electrodes prepared by a two-step electroless plating process in $\mathrm{HNO}_{3}-\mathrm{HCl}$ etching solution with hydrazine reducing agent were uniform and well connected to the electrolyte surface. Conductivity and proton transport rate between Ni-CZI symmetric cell and Pt-CZI symmetric cell were compared by electrochemical impedance spectroscopy and concentration cell test. The total conductivity of the Ni-CZI symmetric cell was $4.131 \times 10^{-4} \mathrm{~S} / \mathrm{cm}$ at $800^{\circ} \mathrm{C}$, and the proton transport rates of the Ni-CZI symmetric cell were all almost $100 \%$ at the operating temperature higher than $400^{\circ} \mathrm{C}$. The nickel electrode prepared by two-step electroless plating was achievable at low cost and had a comparable catalytic performance to that of platinum electrode, indicating it a promising candidate to replace
\end{abstract}

收稿日期：2017-03-13; 收到修改稿日期：2017-04-28

基金项目：国家自然科学基金(51672294, 51372262)

National Natural Science Foundation of China (51672294, 51372262)

作者简介: 温亚兵(1991-)，男，硕士研究生. E-mail: 15151887535@163.com

通讯作者: 温兆银, 研究员. E-mail: zywen@mail.sic.ac.cn; 孟建波, 副研究员. E-mail: mengjianbo@163.com 
the noble platinum catalyst electrode.

Key words: electroless plating; nickel electrodes; high-temperature proton-conducting electrolytes

高温质子导体在氢原、氢传感器、电解水、固 体氧化物燃料电池、有机物加氢及脱氢的膜反应器 等部件具有应用价值，因而引起了广泛关注 ${ }^{[1-4]}$ 。 钯、铂等贵金属及其合金以其良好的氢催化活性、 氢渗透性和高稳定性 ${ }^{[5]}$, 被广泛应用于高温质子导 体的电化学器件中。Uchida 等 ${ }^{[6]}$ 研究了铂电极在高 温质子导体燃料电池应用中的电极极化效应, 结果 表明铂电极作为氢电极时, 在高温质子导体的工作 温度下, 氢电极极化阻抗的大小可忽略不计。但是 贵金属价格昂贵，制备成本高，限制了它们的商业 化应用。涂覆焙烧法的工艺简单，操作方便，是目前 最常用的制造贵金属电极的方法, 但是形成的铂电 极层较厚且均匀性差, 与电解质的结合强度较低, 同时贵金属铂的利用率也比较低。因此减少电极中 铂的担载量, 提高催化剂利用率, 是降低器件成本 的有效途径。

近年来, 人们在过渡金属作为燃料电池催化剂 方面开展了大量研究, 结果表明, 镍等过渡金属表 现出较好的氢催化活性, 并且具有很好的经济性 ${ }^{[7]}$ 。 Acres 等 ${ }^{[8]}$ 总结了常见燃料电池的首选电极, 其中工 作温度高于 $600^{\circ} \mathrm{C}$ 的燃料电池体系均采用镍作为阳 极, 这是因为高温工作条件有利于提升镍电极的反 应动力学性能。目前, 固体氧化物燃料电池的阳极 研究工作多集中于镍电极的修饰, 包括电极组分中 镍和电解质体积比的调控 ${ }^{[9-11]}$, 镍合金的制备 ${ }^{[12-15]}$, 镍电极的形貌设计 ${ }^{[16-17]}$ 等等。将镍等普通金属催化 剂应用于中高温质子导体电极, 减少甚至取代贵金 属铂, 无疑是非常有益的 ${ }^{[18-21]}$ 。

化学镀是一种低成本且成熟的表面处理技术, 与涂覆焙烧法相比, 它的镀层均匀, 附着力强, 对 于任何复杂零件凡是镀液能浸到的部位, 包括微小 孔、盲孔等都可以进行化学镀, 已被广泛应用于各 个行业中 ${ }^{[22-23]}$ 。本工作采用化学镀制备高温质子导 体的镍电极, 研究影响镀层微结构的工艺因素, 并 在此基础上, 进一步比较其与涂覆焙烧法制备的 $\mathrm{Pt}$ 电极的电化学性能。

\section{1 实验方法}

\section{1 $\mathrm{CaZr}_{0.9} \mathrm{In}_{0.1} \mathrm{O}_{3-\delta}$ 高温质子导体的制备}

采用固相法合成 $\mathrm{CaZr}_{0.9} \mathrm{In}_{0.1} \mathrm{O}_{3-\delta}$ (下文以 CZI 代 指)粉体 ${ }^{[24]}$, 首先按化学计量比分别称取 $\mathrm{ZrO}_{2}$ 、
$\mathrm{CaCO}_{3}$ 和 $\mathrm{In}_{2} \mathrm{O}_{3}$ 粉体(均为国药集团化学试剂有限公 司, AR), 以无水乙醇为介质, 在行星式球磨机中球 磨 $20 \mathrm{~h}$ 以降低粉体粒径并使浆料混合均匀。球磨后 的粉体经过笚、干燥后, 分别在 1250 和 $1350^{\circ} \mathrm{C}$ 煅烧 $5 \mathrm{~h}$ 使 $\mathrm{CaCO}_{3}$ 充分分解成 $\mathrm{CaO}$ 并发生固相反应。制 得的粉体经球磨、造粒后采用干压法成型(200 MPa), 得到的片状试样在 $1550^{\circ} \mathrm{C}$ 烧结 $10 \mathrm{~h}$, 获得致密的 CZI 高温质子导体陶瓷片。试样尺寸为 $\Phi 13.00 \mathrm{~mm} \times$ $1.00 \mathrm{~mm}$ 。

\section{2 化学镀前预处理}

镀前预处理步骤包括表面预处理、除油、中和、 化学粗化、敏化、活化和干燥, 每一步完成后都用 去离子水对基底进行清洗, 其中用酸进行粗化刻蚀 后需要进行超声洗涤以除去残留的酸和刻蚀出来的 陶瓷浮渣。具体过程为: 首先选取 CZI 高温质子导 体陶瓷片, 采用 $\mathrm{K}_{2} \mathrm{CrO}_{7}-\mathrm{H}_{2} \mathrm{SO}_{4}$ 混合溶液在室温下 进行酸性除油 1 2 min; 采用 $\mathrm{HNO}_{3}-\mathrm{HCl}$ 混合液刻蚀 10 20 min, 使陶瓷表面粗化; 用 $\mathrm{SnCl}_{2} \cdot 2 \mathrm{H}_{2} \mathrm{O}-\mathrm{HCl}$ 敏化 3 5 min, 再用 $\mathrm{PdCl}_{2}-\mathrm{HCl}$ 活化 5 10 min; 最后 对陶瓷基底进行干燥。

\section{3 化学镀制备 Ni 电极和涂覆焙烧法制 Pt 电极}

称取质量分数约为 $6 \%$ 的四水乙酸镍、 $6.5 \%$ 的 乳酸、3.5\%的 EDTA 和 4\%的 $\mathrm{NaOH}$ (均为国药集团 化学试剂有限公司, AR), 超声处理使固体粉末完全 溶解。将片式 CZI 陶瓷片缠绕一圈胶带以防止陶瓷 侧边的化学镀反应, 将缠好胶带的陶瓷片置于配好 的溶液内进行油浴加热, 使溶液温度达到 $85 \sim 90^{\circ} \mathrm{C}$ 并滴加质量分数为 $6.5 \%$ 的水合肼还原剂, 同时进行 匀速搅拌 $2 \mathrm{~h}$ 便可在 CZI 陶瓷表面得到化学镀制备 的镍电极。

为了进行比较, 采用涂覆焙烧法在 CZI 陶瓷表 面制备 Pt 电极, 即在 CZI 表面均匀涂覆铂浆(PEPt-7840, 贵研铂业股份有限公司), 烘干后在 $800^{\circ} \mathrm{C}$ 焙烧 $1 \mathrm{~h}$ 制得。

\section{4 电极的表征和性能测试}

采用扫描电子显微镜(SEM, S3400N, Hitachi)对 电极表面和断面形貌进行观察分析, 并用能量色散 $\mathrm{X}$ 射线谱仪(Energy Dispersive X-ray Fluoresence Spectrometer, EDS)对电极中的元素进行分析。采用 电化学工作站(Autolab, 瑞士万通)测试带电极的电 解质陶瓷片在各个温度下的交流阻抗谱, 测试条件 为湿氢气气氛 $\left(3 \% \mathrm{H}_{2} \mathrm{O}\right), 10 \mathrm{mV}$ 偏压, $10^{-1} \sim 10^{6} \mathrm{~Hz}$ 频 
率范围。将 Ni-CZI 对称电池密封于陶瓷管一端, 形 成两个独立气室, 在两侧气室中分别通入不同浓度 的氢气, 构成浓差电池, 然后将浓差电池置于高温 电炉中, 采用直流电压表测定电池在不同温度和气 氛下的电动势。

\section{2 结果和讨论}

\section{$2.1 \mathrm{CZI}$ 粉体及陶瓷的相结构和显微结构}

从 XRD 图谱(图 1)中可以看出固相法合成粉体 的陆烧温度为 $1250^{\circ} \mathrm{C}$ 时, 粉体仍存在少量杂相, 当 制烧温度达到 $1350^{\circ} \mathrm{C}$ 时, 可获得纯相的 CZI 粉体。 纯相粉体压制的素坏经 $1550^{\circ} \mathrm{C}$ 烧结 $10 \mathrm{~h}$ 后可获得 纯相 CZI 陶瓷, 由其断面显微结构图(图 2)可以看出, 电解质陶瓷片中晶粒发育良好, 晶粒尺寸在 $2 \sim 4 \mu \mathrm{m}$ 之间，同时陶瓷片非常致密，未见气孔。通过阿基米 德排水法测得该陶瓷的致密度达到 $98.3 \%$, 说明该 陶瓷几乎不存在开气孔, 这与 SEM 分析结果一致。 因而采用 $1350^{\circ} \mathrm{C}$ 敾烧温度和 $1550^{\circ} \mathrm{C}-10 \mathrm{~h}$ 的素坯烧 结制度可获得致密的高温质子导体电解质陶瓷。

\section{2 刻蚀过程中电解质陶瓷的表面形貌变化}

鉴于钙铁矿结构的 CZI 陶瓷的稳定性很高, 实 验选用强络合能力的浓 $\mathrm{HCl}$ 与强氧化性的浓 $\mathrm{HNO}_{3}$ 组合(体积比为 $1: 1$ )配制混合酸液进行刻蚀。从图 3 可以看出, 刻蚀前, 电解质表层平滑(图 3(a)); 经过 $\mathrm{HCl}-\mathrm{HNO}_{3}$ 刻蚀 $10 \mathrm{~min}$ 后, 表层的晶粒凸出且晶粒 结合良好(图 3(b)); 而经过 $\mathrm{HCl}-\mathrm{HNO}_{3}$ 刻蚀 $20 \mathrm{~min}$ 后, 表层的电解质晶粒大面积溶解、脱落, 造成电解 质表层的塌陷(图 3(c)), 且悬浮的晶粒结合力差, 宏 观上表现为陶瓷表面的浮渣易脱落。晶粒凸出且结 合良好的陶瓷表面有利于镀层颗粒的附着和沉积 ${ }^{[25]}$, 因此采用该混合酸刻蚀液刻蚀 $10 \mathrm{~min}$ 可以对 CZI 陶瓷表面进行有效地刻蚀。

\section{3 还原剂对化学镀 Ni 层形貌的影响}

水合肼作为一种不引入任何杂质元素的强还原 剂, 在化学镀等领域应用广泛 ${ }^{[26-28]}$ 。图 4 显示以水

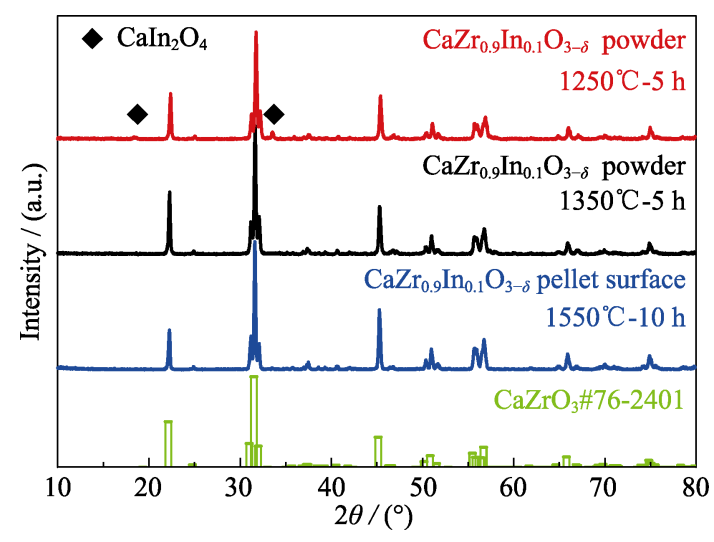

图 1 不同温度炦烧的 CZI 粉体和烧结后陶瓷表面的 XRD 图谱

Fig. 1 XRD patterns of CZI powders calcined at different temperatures and sintered CZI ceramic surface

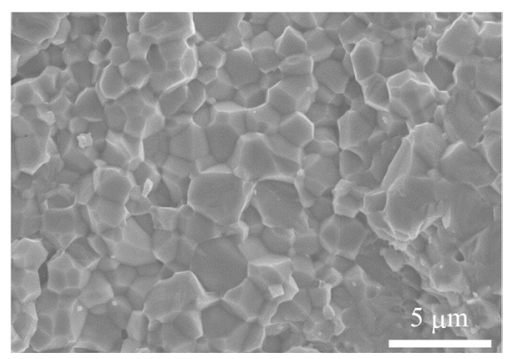

图 $21550^{\circ} \mathrm{C}$ 烧结的 CZI 陶瓷断面形貌

Fig. 2 Cross-sectional microstructure of CZI ceramic sintered at $1550^{\circ} \mathrm{C}$

合肼为还原剂, 经过不同阶段化学镀得到的镍电极 与电解质的断面形貌和表面形貌, 其中图 4(a)为进 行了 $1 \mathrm{~h}$ 的 “一次化学镀” 的电极-电解质的断面形 貌, 从图中可以看出 “一次化学镀” 的镀层疏松, 且 电极与电解质的结合较差, $\mathrm{Ni}$ 颗粒从电解质表面大 量脱落。用蒸馏水对 “一次化学镀” 的片体进行冲 洗, 除去易脱落的 Ni 颗粒并干燥后, 电解质表面留 下了与晶粒结合良好的 $\mathrm{Ni}$ 电极薄层, 如图 4(b, b $\left.\mathrm{b}^{\prime}\right)$ 所示。对该片体进行第二次化学镀, 从图 4(b-f)可以 看出 (以 $0.5 \mathrm{~h}$ 为间隔), 该镍电极层厚度随着 “二次 化学镀” 时间的延长明显增大。当二次化学镀进行
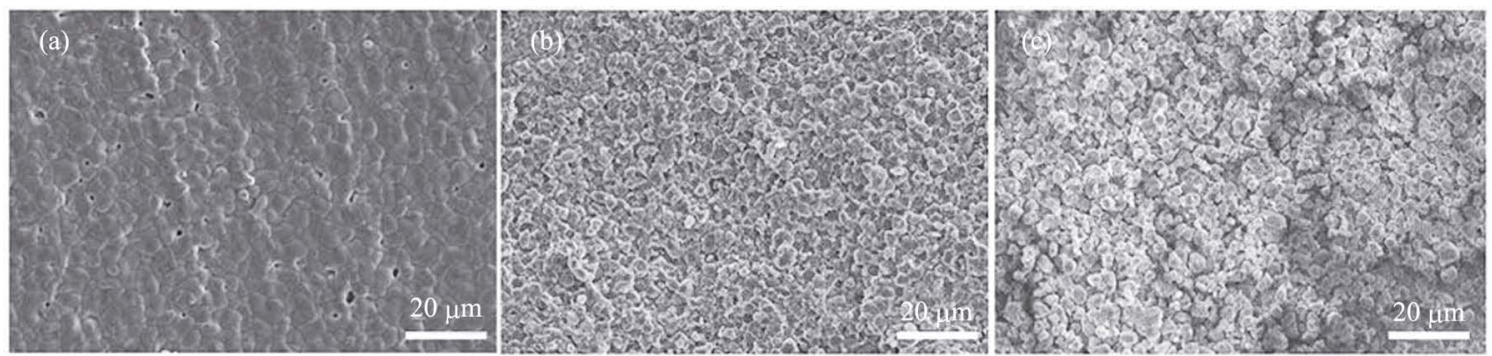

图 $3 \mathrm{HCl}-\mathrm{HNO}_{3}$ 刻蚀不同时间后 CZI 陶瓷的表面形貌

Fig. 3 Morphologies of the CZI surfaces etched for different time (a) Unetched; (b) $\mathrm{HCl}-\mathrm{HNO}_{3}$ etched for $10 \mathrm{~min}$; (c) $\mathrm{HCl}-\mathrm{HNO}_{3}$ etched for $20 \mathrm{~min}$ 

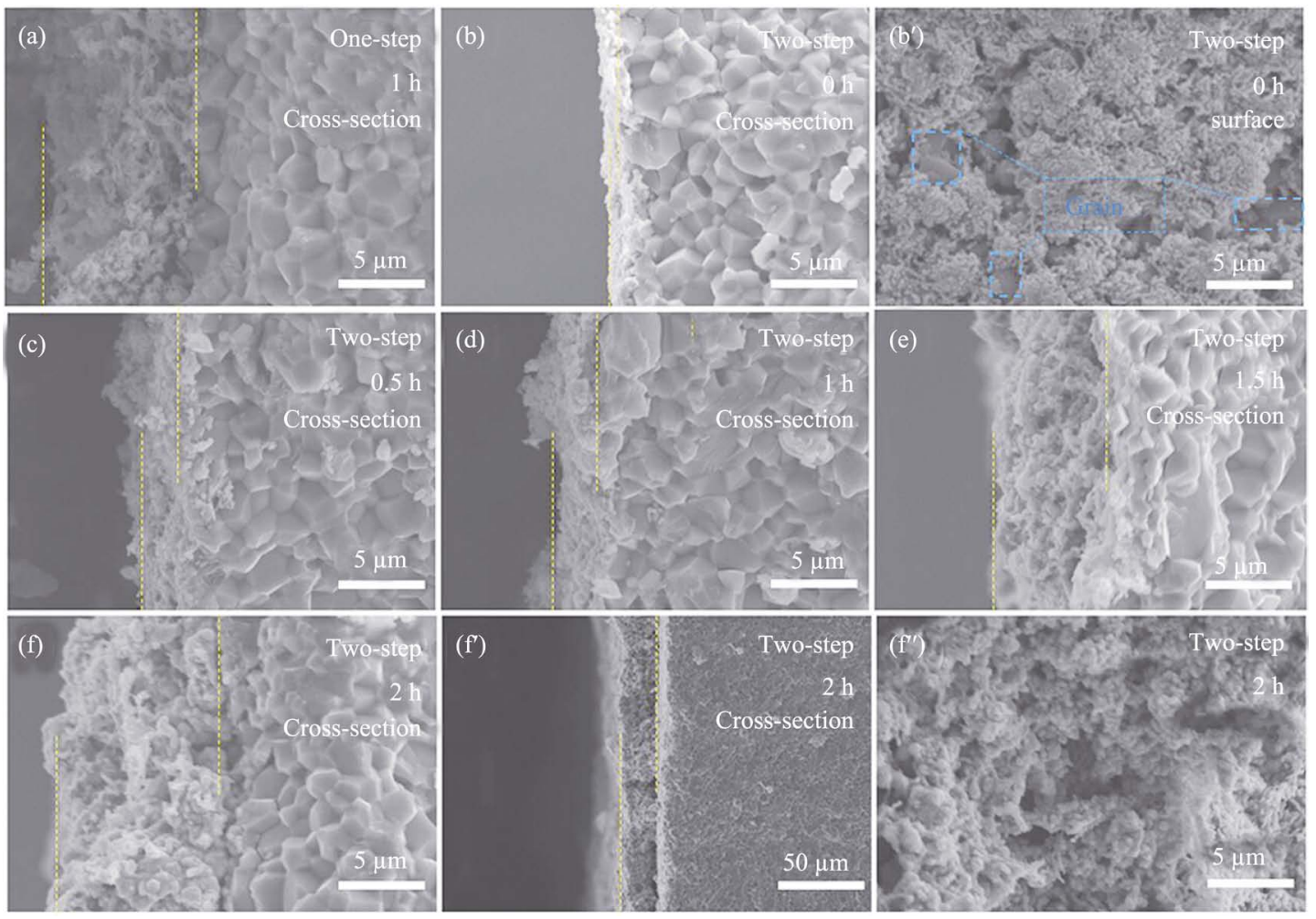

图 4 经过不同阶段化学镀得到的电极断面和表面形貌

Fig. 4 Cross-section and surface morphology of electrodes after electroless plating for different periods (a) One-step, 1 h; (b) Two-step, 0 h; (c) Two-step, 0.5 h; (d) Two-step, 1 h; (e) Two-step, 1.5 h; (f) Two-step, 2 h

到 $2 \mathrm{~h}$ 时，即可获得与电解质结合良好的，厚度约为 $8 \mu \mathrm{m}$ 的镍电极层(图 4(f、 $\mathrm{f}^{\prime}$ ))。“二次化学镀” 完成 后, 从图 4(f")的电极表面形貌可以发现, 该镍电极 层由纳米镍颗粒沉积而成, 且电极中气孔均匀, 有 利于气体的扩散，因而可作为高温质子导体的电极。

图 5(a)为镍电极的 XRD 图谱, 图 5(b)为镍电极 表面的 EDS 面扫描和元素定量分析结果, 结果表明 以水合肼作为还原剂进行化学镀可以制备纯相的镍 电极。

\section{$2.4 \mathrm{Ni}-\mathrm{CZI}$ 和 Pt-CZI 对称电池的电化学阻抗 谱研究}

分别选取以化学镀得到的 $\mathrm{Ni}$ 电极和涂覆焙烧 的铂电极为电极的 CZI 基对称电池来对比研究电极 的电化学性能。以 $50^{\circ} \mathrm{C}$ 为间隔, 测得两种电池在 $300 \sim 800^{\circ} \mathrm{C}$ 温度区间的阻抗, 分别选取 $300^{\circ} \mathrm{C} 、 600^{\circ} \mathrm{C}$ 和 $800^{\circ} \mathrm{C}$ 下二者的阻抗进行归一化处理后作出了 如图 6 所示的电化学阻抗谱。从不同温度下的电化 学阻抗谱看出, 随着温度升高, 相应的高温质子导 体的阻抗大幅下降，电导率明显升高。

由 $\sigma=\frac{L}{R S}$ ( $R$ 为体系阻抗, $L$ 为样品厚度, $S$ 为样 品横截面积, $\sigma$ 为样品电导率)计算得到陶瓷片的总 电导率。将电导率与绝对温度的倒数绘图得到 Arrhenius
曲线, 如图 7 所示即为湿氢气气氛下总电导率的 Arrhenius 曲线。

从图 6 可以看出, 不同电极的陶瓷片阻抗谱中 晶粒和晶界阻抗分布并不相同, 低温下, 铂的催化 活性远高于镍, 铂电极的催化反应速率也更快, 陶 瓷中有更多的载流子，导致铂电极质子导体的晶粒 和晶界阻抗较低; 高温下, 镍的催化活性提高, 阻 抗谱也基本反映了材料的本征特性。从图 7 中可以 看出, 接近高温时, 两种电极的高温质子导体电导 率更为接近, 即低温下 $\mathrm{Ni}$ 电极比 $\mathrm{Pt}$ 电极的催化活 性低, 而当工作温度升高到 $600^{\circ} \mathrm{C}$ 以上时, $\mathrm{Ni}$ 电极的 催化活性几乎与 $\mathrm{Pt}$ 电极相等。当工作温度为 $800^{\circ} \mathrm{C}$ 时, $\mathrm{Pt}$ 电极质子导体的总电导率为 $5.503 \times 10^{-4} \mathrm{~S} / \mathrm{cm}$, 而 $\mathrm{Ni}$ 电极质子导体总电导率则达到了 $4.131 \times 10^{-4} \mathrm{~S} / \mathrm{cm}$, 二者相差无几，与文献报道值较为接近 ${ }^{[29]}$ 。而由图 7 两条曲线斜率拟合得到的活化能也几乎完全相同, 反映了材料的本征特性, 说明 $\mathrm{Ni}$ 电极具有足够的催 化活性。

\section{5 基于 $\mathrm{Ni}$ 电极的氢浓差电池测试}

质子导体在还原气氛中的质子迁移率一般通过 浓差电池的电动势(EMFs)来测定计算。因此, 我们 以化学镀的 $\mathrm{Ni}$ 层为电极, CZI 作为电解质, 构筑氢 浓差电池。电极两侧的气体分别采用纯氢气 $+5 \% \mathrm{H}_{2} / \mathrm{Ar}$ 

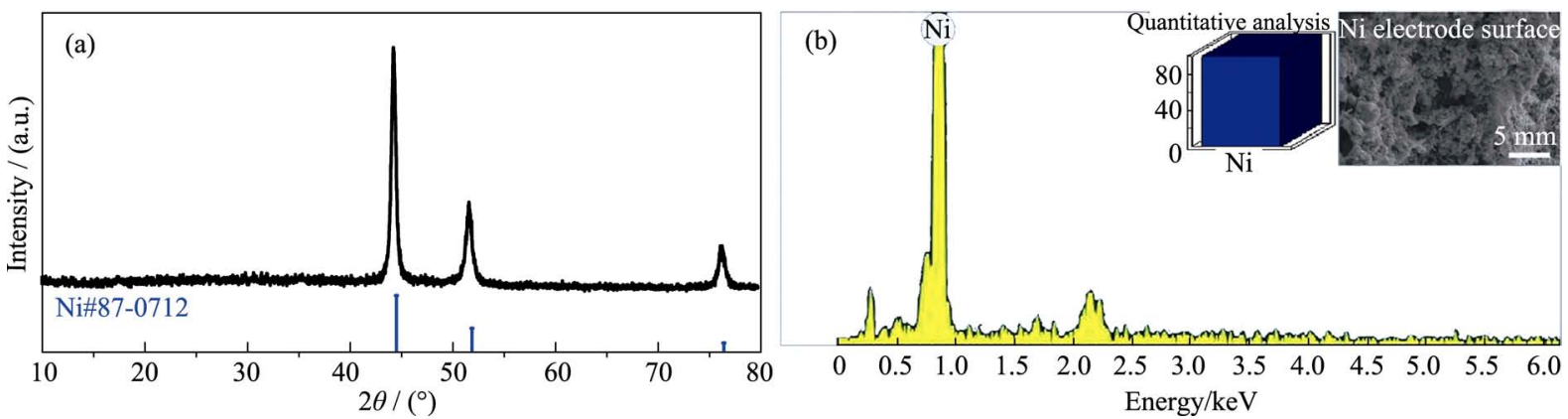

图 5 镍电极的 XRD 图谱(a)和镍电极表面的 EDS 面扫描图(b)

Fig. 5 XRD pattern of Ni electrode (a) and EDS plane scan analysis of Ni electrode surface (b)
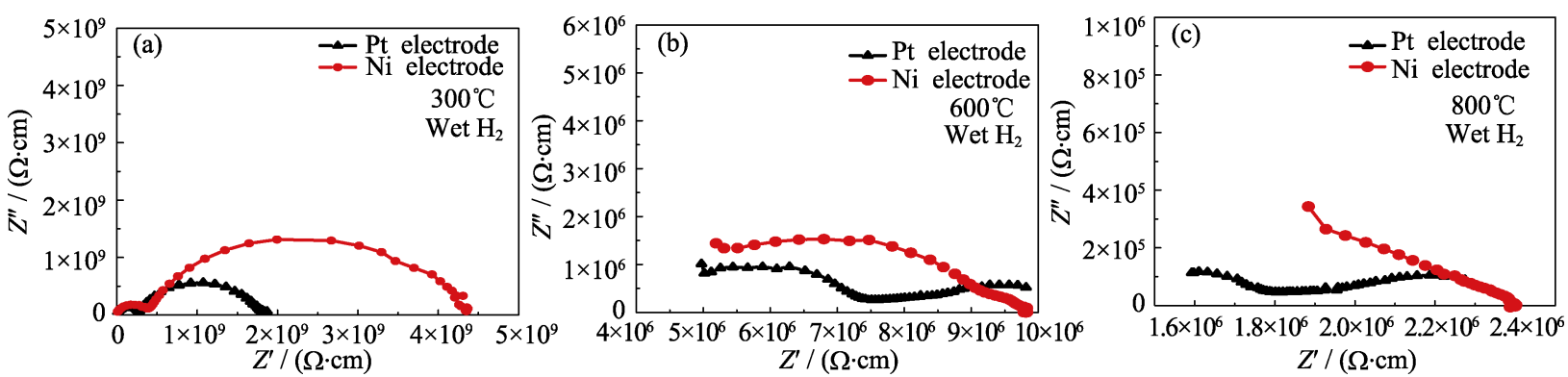

图 6 湿氢气气氛中 Pt-CZI 和 Ni-CZI 在不同温度下的电化学阻抗谱

Fig. 6 Impedance spectra of Pt-CZI and Ni-CZI at different temperatures in wet $\mathrm{H}_{2}$

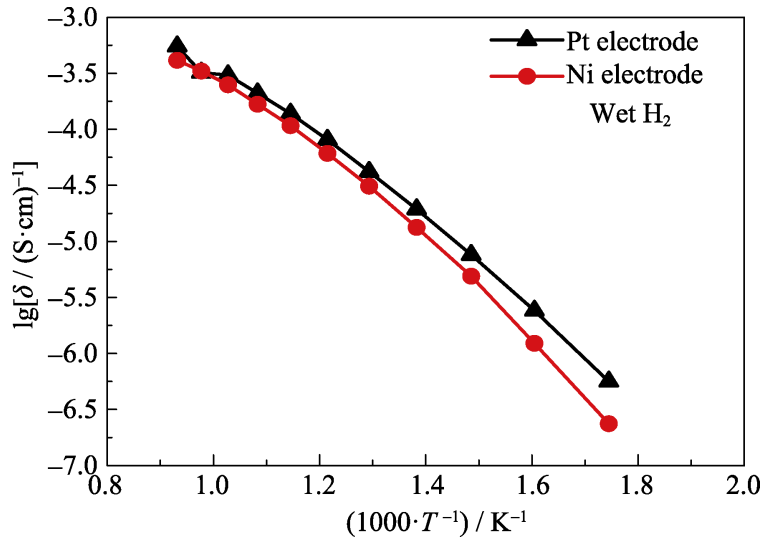

图 7 以涂覆焙烧 $\mathrm{Pt}$ 和化学镀 $\mathrm{Ni}$ 为电极的高温质子导体在 湿氢气气氛下总电导率的 Arrhenius 曲线

Fig. 7 Arrhenius curves of total conductivity of pasted Pt and electroless plated $\mathrm{Ni}$ electrode high-temperature proton conductor in wet $\mathrm{H}_{2}$

混合气以及 $50 \% \mathrm{H}_{2} / \mathrm{N}_{2}$ 混合气 $+5 \% \mathrm{H}_{2} / \mathrm{Ar}$ 混合气。 氢分压高的一侧电极为阳极, 氢分压低的一侧则 为阴极。

如果电解质为纯质子导电的材料, 则可以根据 Nernst 方程计算其理论电动势: $E^{\theta}=\frac{\mathrm{R} T}{2 \mathrm{~F}} \ln \frac{P_{\mathrm{H}_{2}}(\mathrm{I})}{P_{\mathrm{H}_{2}} \text { (II) }}$, 其中 $P_{\mathrm{H}_{2}}(\mathrm{I})$ 和 $P_{\mathrm{H}_{2}}(\mathrm{II})$ 分别代表阳极和阴极的氢分压, $\mathrm{R} 、 T$ 和 $\mathrm{F}$ 分别代表气体常数、温度和法拉第常数。 实际所测得的电动势值与理论电动势 $\mathrm{EMF}$ 对比如 图 8 所示, 其中 $E_{1}\left(100 \% \mathrm{H}_{2}-5 \% \mathrm{H}_{2}\right)$ 为纯氢气

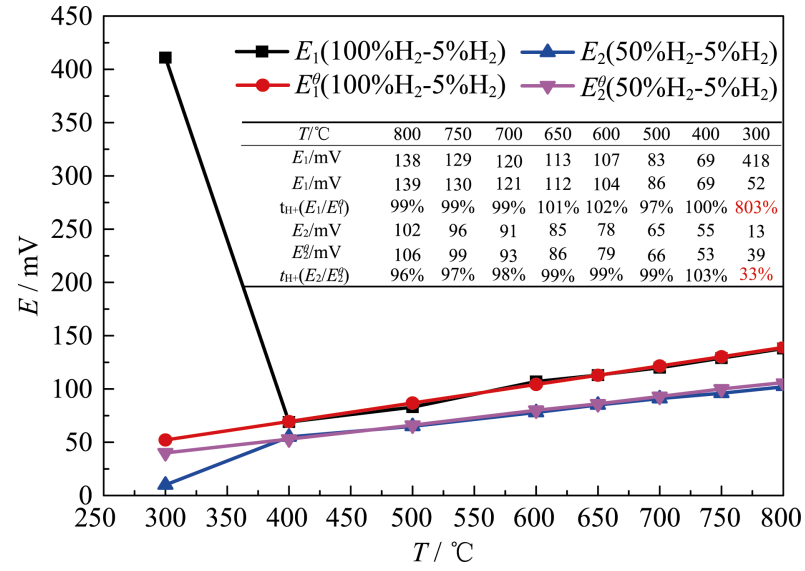

图 8 浓差电池 $\mathrm{H}_{2}\left(P_{\mathrm{H}_{2}}=10^{5} \mathrm{~Pa}\right) / \mathrm{H}_{2}+\mathrm{N}_{2}\left(P_{\mathrm{H}_{2}}=5 \times 10^{4} \mathrm{~Pa}\right), \mathrm{Ni}$ | $\mathrm{CZI} \mid \mathrm{Ni}, \mathrm{H}_{2}+\operatorname{Ar}\left(P_{\mathrm{H}_{2}}=5 \times 10^{3} \mathrm{~Pa}\right)$ 的电动势、理论电动势和质子迁 移率

Fig. 8 EMFs, theoretical electromotive force values and proton transport rates of hydrogen concentration cell: $\mathrm{H}_{2}\left(P_{\mathrm{H}_{2}}=10^{5} \mathrm{~Pa}\right) /$ $\mathrm{H}_{2}+\mathrm{N}_{2}\left(P_{\mathrm{H}_{2}}=5 \times 10^{4} \mathrm{~Pa}\right), \mathrm{Ni}|\mathrm{CZI}| \mathrm{Ni}, \mathrm{H}_{2}+\mathrm{A}_{\mathrm{r}}\left(P_{\mathrm{H}_{2}}=5 \times 10^{3} \mathrm{~Pa}\right)$

$+5 \% \mathrm{H}_{2} / \mathrm{Ar}$ 混合气的实测电动势, $E_{1}^{\theta}\left(100 \% \mathrm{H}_{2}-5 \% \mathrm{H}_{2}\right)$ 为纯氢气 $+5 \% \mathrm{H}_{2} / \mathrm{Ar}$ 混合气的理论电动势; $\mathrm{E}_{2}\left(50 \% \mathrm{H}_{2}-\right.$ $\left.5 \% \mathrm{H}_{2}\right) 、 E_{2}^{\theta}\left(50 \% \mathrm{H}_{2}-5 \% \mathrm{H}_{2}\right)$ 则分别为 $50 \% \mathrm{H}_{2} / \mathrm{N}_{2}$ 混合 气 $+5 \% \mathrm{H}_{2} / \mathrm{Ar}$ 混合气的实测和理论电动势。而浓差电 池的质子迁移率 $t_{\mathrm{H}^{+}}$则根据公式 $t_{\mathrm{H}^{+}}=\frac{E_{\text {实测 }}}{E^{\theta}}$ 计算。由 图 8 可知, Ni-CZI 对称电池在 $400 \sim 800^{\circ} \mathrm{C}$ 的实测电动 势值均近似于理论电动势值的 $100 \%$ ，即在 400 
$800^{\circ} \mathrm{C}$ 的温度区间内, Ni-CZI 对称电池的质子迁移率 近似 $100 \%$ 。而 $300^{\circ} \mathrm{C}$ 时, 不同气氛下实测电动势与 理论电动势均差别较大, 结合图 6(a)和图 7 中 $300^{\circ} \mathrm{C}$ 时体系的电导率较低, 说明低于 $300^{\circ} \mathrm{C}$ 时, $\mathrm{Ni}$ 电极的 催化活性较低, 无法使 $\mathrm{H}_{2}$ 解离成质子, 而当体系处 于高于 $400^{\circ} \mathrm{C}$ 温度下, $\mathrm{Ni}$ 电极的催化活性均可使 $\mathrm{H}_{2}$ 解离。结合图 7 和图 8 说明两种高温质子导体的活 化能随着温度的升高趋于相同, 这与某一温度下相 同材料体系活化能不变相符, 该结果也印证了相同 材料体系的不同单体, 可能因为电极和显微结构的 不同, 在测试过程中存在如图 6 表现的某些温度段 的电化学性能差异。

图 9 为浓差电池 $\left(50 \% \mathrm{H}_{2}-5 \% \mathrm{H}_{2}\right)$ 在 $800^{\circ} \mathrm{C}$ 下运行 不同时间后的电解质/电极的界面形貌, 从图中看出 随着运行时间的增加, 一直到 $48 \mathrm{~h}$ 后电极和电解质 仍未发生明显的分离, 说明化学镀制得的 $\mathrm{Ni}$ 电极与 电解质的界面结合良好且稳定, 可作为电极应用于 高温质子导体。

\section{3 结论}

以水合肼为还原剂, 通过二次化学镀在 CZI 高 温质子导体陶瓷表面制备均匀且界面结合良好的纯 $\mathrm{Ni}$ 电极, 电极镀层厚度约为 $8 \mu \mathrm{m}$, 电极中气孔分布 均匀, 电极在高温氢气气氛中具有较好的催化活 性。实验测量并比较了化学镀 $\mathrm{Ni}$ 电极高温质子导体 与涂覆铂电极高温质子导体在不同温度下的电化学 阻抗谱, 发现在 $600^{\circ} \mathrm{C}$ 以上工作温度时, 两质子导 体的总电导率相近且计算所得的活化能几乎相同; $800^{\circ} \mathrm{C}$ 工作温度时, Pt、Ni 电极高温质子导体的总电

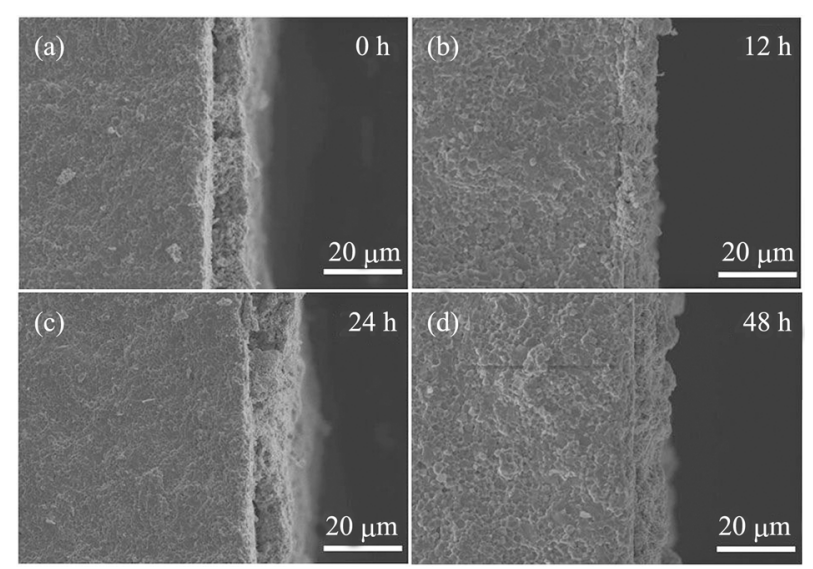

图 9 浓差电池 $\left(50 \% \mathrm{H}_{2}-5 \% \mathrm{H}_{2}\right)$ 在 $800{ }^{\circ} \mathrm{C}$ 下, 运行不同时间的 电解质/电极的界面形貌

Fig. 9 Interface morphology of electrolyte and electrode of concentration cell $\left(50 \% \mathrm{H}_{2}-5 \% \mathrm{H}_{2}\right)$ with different run time at $800^{\circ} \mathrm{C}$
导率分别为 $5.503 \times 10^{-4}$ 和 $4.131 \times 10^{-4} \mathrm{~S} / \mathrm{cm}$ 。采用该 $\mathrm{Ni}$ 电极的 CZI 电解质构筑氢浓差电池, 各个温度 和气氛条件下测得的电动势与计算的理论值几乎 完全一致。以上结果说明, 使用该 $\mathrm{Ni}$ 电极取代 $\mathrm{Pt}$ 电极, 可以得到性能相近而成本更低的高温质子导 体器件。

\section{参考文献:}

[1] SCHOBER T. Applications of oxidic high-temperature proton conductors. Solid State Ionics, 2003, 162(1): 277-281.

[2] NOWICK A S, VAYSLEYB A V. Isotope effect and proton hopping in high-temperature protonic conductors. Solid State Ionics, 1997, 97(1): 17-26.

[3] WEN Z Y, LI J Z. New applications of solid state ionics. Journal of Inorganic Materials, 2013, 28(11): 1163-1164.

[4] MATSUMOTO H, OKUBO M, HAMAJIMA S, et al. Extraction and production of hydrogen using high-temperature proton conductor. Solid State Ionics, 2002, 152(12): 715-720.

[5] COLLINS J P, WAY J D. Preparation and characterization of a composition palladium-ceramic membrane. Industrial \& Engineering Chemistry Research, 1993, 32(12): 3006-3013.

[6] UCHIDA H, TANAKA S, IWAHARA H. Polarization at Pt electrodes of a fuel cell with a high temperature-type proton conductive solid electrolyte. Journal of Applied Electrochemistry, 1985, 15(1): 93-97.

[7] NARAYANAN T, BASKARAN I, KRISHNAVENI K, et al. Deposition of electroless Ni-P graded coatings and evaluation of their corrosion resistance. Surface \& Coatings Technology, 2006, 200(11): 3438-3445.

[8] ACRES G J K, HARDS G A. Electrocatalysts for fuel cells. Philosophical Transactions of the Royal Society a-Mathematical Physical and Engineering Sciences, 1996, 354(1712): 1671-1680.

[9] LEE J H, MOON H, LEE H W, et al. Quantitative analysis of microstructure and its related electrical property of SOFC anode, Ni-YSZ cermet. Solid State Ionics, 2002, 148(1/2): 15-26.

[10] KOIDE H, SOMEYA Y, YOSHIDA T, et al. Properties of Ni/YSZ cermet as anode for SOFC. Solid State Ionics, 2000, 132(3/4): 253-260.

[11] ARUNA S T, MUTHURAMAN M, PATIL K C. Synthesis and properties of Ni-YSZ cermet: anode material for solid oxide fuel cells. Solid State Ionics, 1998, 111(1/2): 45-51.

[12] KIM H, LU C, WORRELL W L, et al. Cu-Ni cermet anodes for direct oxidation of methane in solid-oxide fuel cells. Journal of the Electrochemical Society, 2002, 149(3): A247-A250.

[13] GRGICAK C M, PAKULSKA M M, O'BRIEN J S, et al. Synergistic effects of $\mathrm{Ni}_{1-\mathrm{x}} \mathrm{Co}_{\mathrm{x}}-\mathrm{YSZ}$ and $\mathrm{Ni}_{1-x} \mathrm{Cu}_{x}$-YSZ alloyed cermet SOFC anodes for oxidation of hydrogen and methane fuels containing $\mathrm{H}_{2} \mathrm{~S}$. Journal of Power Sources, 2008, 183(1): 26-33. 
[14] AN W, GATEWOOD D, DUNLAP B, et al. Catalytic activity of bimetallic nickel alloys for solid-oxide fuel cell anode reactions from density-functional theory. Journal of Power Sources, 2011, 196(10): 4724-4728

[15] KAN H, LEE H. Sn-doped Ni/YSZ anode catalysts with enhanced carbon deposition resistance for an intermediate temperature SOFC. Applied Catalysis B-Environmental, 2010, 97(1/2): 108-114.

[16] FUKUI T, MURATA K, OHARA S, et al. Morphology control of Ni-YSZ cermet anode for lower temperature operation of SOFCs. Journal of Power Sources, 2004, 125(1): 17-21.

[17] HWANG C, YU C H. Formation of nanostructured YSZ/Ni anode with pore channels by plasma spraying. Surface \& Coatings Technology, 2007, 201(12): 5954-5959.

[18] WANG C, DAIMON H, ONODERA T, et al. A general approach to the size- and shape-controlled synthesis of platinum nanoparticles and their catalytic reduction of oxygen. Angewandte ChemieInternational Edition, 2008, 47(19): 3588-3591.

[19] VIDAL-IGLESIAS F J, SOLLA-GULLON J, RODRIGUEZ P, et al. Shape-dependent electrocatalysis: ammonia oxidation on platinum nanoparticles with preferential (100) surfaces. Electrochemistry Communications, 2004, 6(10): 1080-1084.

[20] SHAO Y, YIN G, WANG Z, et al. Proton exchange membrane fuel cell from low temperature to high temperature: material challenges. Journal of Power Sources, 2007, 167(2): 235-242.

[21] ATTARD G S, BARTLETT P N, COLEMAN N R B, et al. Mesoporous platinum films from lyotropic liquid crystalline phases. Science, 1997, 278(5339): 838-840.
[22] NIESEN T P, DE GUIRE M R. Review: deposition of ceramic thin films at low temperatures from aqueous solutions. Journal of Electroceramics, 2001, 6(3): 169-207.

[23] TANG Y, LIU Y, SAMPATHKUMARAN U, et al. Particle growth and particle-surface interactions during low-temperature deposition of ceramic thin films. Solid State Ionics, 2002, 151(1/4): 69-78.

[24] HAN J, WEN Z, ZHANG J, et al. Fabrication of dense $\mathrm{CaZr}_{0.90} \mathrm{In}_{0.10} \mathrm{O}_{3 \text {-delta }}$ ceramics from the fine powders prepared by an optimized solid-state reaction method. Solid State Ionics, 2008, 179(21-26): 1108-1111.

[25] NATIVIDAD E, LATASTE E, LAHAYE M, et al. Chemical and morphological study of the sensitisation, activation and $\mathrm{Cu}$ electroless plating of $\mathrm{Al}_{2} \mathrm{O}_{3}$ polycrystalline substrate. Surface Science, 2004, 557(1/2/3): 129-143.

[26] BASKARAN I, NARAYANAN T S N S, STEPHEN A. Effect of accelerators and stabilizers on the formation and characteristics of electroless Ni-P deposits. Materials Chemistry and Physics, 2006, 99(1): $117-126$.

[27] CHEONG W J, LUAN B L, SHOESMITH D W. The effects of stabilizers on the bath stability of electroless Ni deposition and the deposit. Applied Surface Science, 2004, 229(1-4): 282-300.

[28] EL MAHALLAWY N, BAKKAR A, SHOEIB M, et al. Electroless Ni-P coating of different magnesium alloys. Surface \& Coatings Technology, 2008, 202(21): 5151-5157.

[29] KURITA N, FUKATSU N, ITO K, et al. Protonic conduction domain of indium-doped calcium zirconate. Journal of the Electrochemical Society, 1995, 142(5): 1552-1559. 